\title{
Diablotexto
}

\section{La "línea clara" en la poesía de Luis Alberto de Cuenca: derroteros de un extraño encuentro}

\author{
"Clear line" in Luis Alberto de Cuenca's poetry: courses of an extrange \\ encounter
}

\author{
FACUNDO GIMÉNEZ \\ (UNIVERSIDAD NACIONAL de MAR del Plata)
}

\begin{abstract}
Resumen: El siguiente trabajo se propone abordar la apropiación poética de la expresión "línea clara", proveniente del ámbito historietístico, que realiza el poeta español Luis Alberto de Cuenca (Madrid, 1950). Nuestro análisis se centrará en dos aspectos fundamentales de dicha apropiación. El primero será aquel vinculado con su inscripción en un contexto histórico, cultural, político y social particular: el del regreso de la democracia en España. Desde este punto de vista, la emergencia de una "línea clara" luisalbertiana será estudiada como la construcción de un espacio consensuado y convencional -pacto de lectura- en el que la experiencia poética se vuelve, otra vez, accesible. El segundo aspecto abordado será el de la postulación de una dimensión "cómplice" del texto poético, que permitirá comprender los alcances del planteo luisalbertiano.
\end{abstract}

Palabras clave: Luis Alberto de Cuenca, Línea clara, Pacto de lectura, Complicidad

Abstract: The purpose of this current paper is to analyse the poetic appropriation of the comic expression "clear line" made by the spanish writer Luis Alberto de Cuenca (Madrid, 1950). Our approach will focus on two main aspects of this appropriation. The first one is related to the historic, cultural, political and social context in which this expression began to be used by de Cuenca: the return of democracy in Spain. From this point of view, its appearance will be studied as the construction of a consensual and convencional space -a reading pact- in which poetic experience can be, again, accessible. The second aspect will be the "complicit" dimension of the poetic text, which will allow us to understand the scope of Luis Alberto de Cuenca's appropriation.

Key words: Luis Alberto de Cuenca, Clear line, Reading pact, Complicity 


\section{Introducción: el encuentro de la "línea clara" y Luis Alberto de Cuenca}

Probablemente uno de los encuentros más singulares y productivos de la cultura española de finales de siglo $X X$ sea el que tiene como protagonistas a la poesía de Luis Alberto de Cuenca y a la "línea clara" de Georges Remi, también conocido como Hergé. El "principio de esta hermosa amistad" aparece narrado en el prólogo que De Cuenca escribe al libro Tintín-Hergé (2011) de Fernando Castillo Cáceres. Allí, el escritor madrileño explica que fue recién hacia 1980, "cuando frisaba la treintena," que descubrió, en una conversación con el crítico Juan Manuel Bonet, "la gran trascendencia de la 'línea clara' en el cómic" y que fue también por entonces cuando comenzó a indagar en torno a las implicancias de la propuesta hergiana. (De Cuenca, 2011: 9).

La escuela de la ligne claire surgió en Bruselas durante el periodo de entreguerras y en las décadas sucesivas adquirió una popularidad tan desbordante y un desarrollo técnico tan espectacular que se propagó mundialmente. Entre sus filas, además del mencionado Hergé, es posible contar a historietistas y dibujantes de la talla de Edgar P. Jacobs, Jacques Martin o Bob de Moor. Si bien el nombre de esta escuela fue acuñado por Joost Swarte en la década del setenta, la idea de la "línea clara" evidentemente responde a una impresión visual que ya era reconocible en la producción bruselense de la década del treinta. Sus rasgos definitorios eran la inclinación por el trazo limpio, continuo e idéntico, la preeminencia por los colores planos, sin sombras ni volúmenes, y cierta aspiración al realismo y al detalle ${ }^{1}$. Tal como acertadamente advierte Pierre Fresnault-Deruelle, se trata de un estilo que, bajo una apariencia sencilla y transparente, no deja de ofrecer algunos procedimientos de "protocolos sumamente estrictos, bien estabilizados, donde la verosimilitud de motivos se sustenta en la rigurosidad del trazo" (1999: 11). Surgida a mediados de los años veinte, en el contexto artístico de la "vuelta al orden", la "línea clara" apuesta por la aminoración del entusiasmo vanguardista

\footnotetext{
${ }^{1}$ Benoit Peeters, a partir del análisis del uso del color que realiza la línea clara, explica cómo el trazo "claro" implica, sino una merma en la sorpresa de la línea, al menos sí una negociación: "al contrario de todo lo que la pintura desarrolla a partir de Turner y los impresionistas, en Hergé el color no busca reflejar una percepción sino más bien una concepción. Por tanto, opera -es su fuerza, pero quizá también su debilidad- como un mero refuerzo del trabajo del trazo. Redibuja, convierte las líneas en superficie." (Peeters, 2013: 228)
} 
y el regreso a lo clásico, al dibujo ingresiano, preocupado por la línea, aunque sin renunciar al lenguaje de la modernidad (Castillo Cáceres 2011: 16).

El carácter extraño -e inclusive, intempestivo- que podría estar asociado al encuentro entre Luis Alberto de Cuenca y la historieta de Hergé probablemente provenga de la identificación del noveno arte y, en particular, de los álbumes de Tintín, con un público exclusivamente infantil ${ }^{2}$. Lo cierto es que, con el transcurso de las décadas, en el caso de las historietas de Tintín, esta identificación ha sido, al menos, problematizada. En este sentido, si bien su lectorado en un principio se asoció efectivamente al público infantil, el desarrollo de una técnica y una narrativa cada vez más sofisticadas posibilitó, desde la posguerra, la inclusión del público adulto ${ }^{3}$. Como corolario de este proceso, a su vez, esa impronta artística fue captada, casi de inmediato, por el arte Pop de la década del sesenta y setenta, lo que trajo consigo, por un lado, que la crítica volviera su mirada hacia este estilo y, por otro, que hubiera una generalizada reivindicación museística cuyo principal hito fue la muestra de Bruselas intitulada El museo imaginario de Tintín de 1979. Este proceso de consagración institucional de la ligne claire y en particular de la obra de Hergé, para 1980, cuando Juan Manuel Bonet conversa con Luis Alberto de Cuenca ya es un hecho. En España, además, estaba a punto de salir, el año siguiente, una revista como El Cairo (1981-1984; 1985-1991), dedicada a ofrecer una perspectiva adulta y posmoderna de la "línea clara" (Alary, 2002). Por otra

\footnotetext{
2 La asociación entre historieta y público infantil pone en evidencia la conflictividad de este tipo de asociaciones. En esta dirección, Juan Cervera en su Teoría de la literatura infantil ofrece una distinción entre "literatura ganada" por una lectura infantil y aquella "literatura creada para niños" (1992:18). La noción de "literatura ganada", que explica la recuperación por parte de un público infantil de una literatura que había estado destinada previamente a un público adulto, permite reflexionar en torno a la movilidad de estas conexiones que se cristalizan en la cultura. En otras palabras, esta noción colabora para comprender cómo aquellos textos que fueron destinado a adultos pueden ser leídos (ganados o recuperados) por niños y, por extensión, cómo aquella literatura creada para niños puede ser también leída por adultos.

${ }^{3}$ Para comprender esta asociación entre Las aventuras de Tintín con el público infantil es importante observar qué espacios de difusión periódica y serialización tuvo su obra. En este sentido, los primeros textos que realiza Hergé son publicados en el suplemento infantil de Le Vingtième Siècle, Le Petit Vingtième (1929-1939). La segmentación del público en este apartado del diario, sumado a una narración iterativa y sustentada en el recurso del gag de esas primeras aventuras, y a un verdadero éxito entre el público más joven afianzó esta identificación. Del mismo modo, la creación de la revista Le Journal de Tintin (1946-1993), cuyo horizonte etario apuntaba también al público infantil, acabó por demarcar esa zona. En sintonía con esta difusión destinada al público infantil, los derechos en España de Las aventuras de Tintín fueron adquiridos por la editorial Juventud especializada en literatura infantojuvenil.
} 
parte, faltaba también muy poco tiempo para la tan polémica como publicitada exposición que la fundación Miró le dedicaría a Tintín en 19844.

Otro dato que resulta sumamente importante del encuentro con Juan Manuel Bonet, es que Luis Alberto de Cuenca, en esos años, está por alejarse de forma definitiva de la impronta novísima que había caracterizado a sus primeros libros, Los retratos (1971), Elsinore (1972) y Scholia (1978). De hecho, desde 1979, está en el proceso de redacción de La caja de plata (1985), un poemario que comenzará a emparentar su poesía, en un giro copernicano, con la producción escrituraria que dominará las décadas del ochenta y noventa, caracterizada por su clasicismo, la claridad expositiva y por un pacto lector, por usar expresión barthesiana, "amistoso". En este contexto, podríamos sospechar que la "línea clara" se le presenta como la alegoría de un estilo que apela al clasicismo para contener el declive del estruendo vanguardista. De todos modos y más allá de cualquier especulación, el acercamiento a la "línea clara" que hace el autor español no se quedará en el mero homenaje o en la crítica del arte. Por el contrario, con el paso de los años, esta expresión comenzará a calibrarse desde una perspectiva poética. En otras palabras, Luis Alberto de Cuenca comenzará a asociar este estilo con cierta forma de poetizar propia, en particular la que tiene su escritura posterior a La caja de plata. Esta asociación se hará, a lo largo de los años, más apreciable, al punto que, en diversas ocasiones, él mismo se declarará un "poeta de línea clara" (Tendero, 2008).

Uno de los rasgos más singulares de la línea clara luisalbertiana, más allá de su uso como sinónimo de asequibilidad lectora o claridad expositiva, es la forma en que se articula como estrategia autoral. Ello puede apreciarse, por un lado, en un insistente abordaje de la expresión en los poemas y, por otro lado, en su presencia en textos antológicos como, por ejemplo, Los poetas de la línea clara, un suplemento que redactó entre 1995 y 1996 para Nueva Revista de Política. Respecto de su fortuna, por otra parte, es importante mencionar que esta estrategia autoral, cuyo hito fundacional podemos imaginar

\footnotetext{
${ }^{4}$ Nos referimos a la muestra Tintín a Barcelona. Homenatge a Hergé. El Museu Imaginari de Tintín, ofrecida entre septiembre y noviembre de 1984 por la Fundación Joan Miró (Bufill et al., 1984).
} 
en ese encuentro con Juan Manuel Bonnet, tiene un éxito notable y que será aceptado, sin mayores inconvenientes, por la crítica hispánica que lo usará para explicar su producción posterior a La caja de plata (Arroyo Almaraz, 2012; Lanz, 2006; Letrán, 2005; Suárez Martínez, 2010). En este sentido, la fortuna del término se debe a dos razones. La primera está vinculada con la recuperación de las formas y contenidos de los mass media que, en su poesía, a partir de la década del ochenta, se presenta al mismo tiempo como democrática y posmoderna (Letrán, 2005). El acercamiento, de este modo, de su poesía a la "línea clara" puede comprenderse como la verificación de cierta reversibilidad entre las denominadas "alta" y "baja” cultura. La segunda se vincula con la recuperación de, si no el realismo, al menos sí de la figuración en su poesía. En esta dirección, la "línea clara" se presenta como modelo de cierta recuperación realista, que es comprendida, tal como lo hacía la "línea clara" hergiana, como el simulacro técnico de un efecto.

El descubrimiento de la "línea clara", como se dijo previamente, marca un momento fundacional en su poesía, porque es precisamente la comprensión y apropiación poética de la estética de "línea clara" la que modelará no solamente una forma de comprender el dispositivo poético sino además una forma de comprender la cultura. Al mismo tiempo, es importante reconocer cierto uso estratégico en la difusión de esta expresión que va a funcionar, en un periodo tan aparentemente homogéneo como las décadas del ochenta y noventa, como la demarcación de un espacio diferencial para su poesía, que se alimentará de la cercanía y el arrastre de las poéticas de la experiencia pero que no acabará confundiéndose con ellas ${ }^{5}$. Por último, la vinculación de sus poemarios posteriores a La caja de plata con la "línea clara" -algo que, como dijimos, comenzará a proponer el poeta y que será casi de inmediato aceptado

\footnotetext{
${ }^{5}$ Este emplazamiento estratégico que propone la "línea clara" luisalbertiana puede pensarse a la manera de un enclave en la "poesía de la experiencia" que le permite, por un lado, emparentarse con dicha producción dominante aprovechando su difusión y, por otro lado, establecer una distancia sutil que admita una relevancia autoral. En este sentido, no sería equivocado afirmar que la gran diferencia - $y$, en cierta forma, su complementariedad- con la poesía de la experiencia radica en la focalización en el dispositivo retórico. Así opina Marta Sanz Pastor, quien pone en duda que la "línea clara" pueda emparentarse, sencillamente, con la poesía de la experiencia: "tal vez la línea clara no sea sinónimo de rehumanización, sino sencillamente de legibilidad" (Sanz 2007, 57:53). En esta dirección, Ana Eyre recupera la denominación de posnovísimo (Villena) o de poeta figurativo (García Martín) para establecer una distancia con aquella otra producción (2003).
} 
por la crítica- va a funcionar como un corte de aguas respecto de su producción previa, que, en lo sucesivo, pasará a ser postergada o suprimida de diversos recortes antológicos dedicados al autor.

El presente trabajo tiene el propósito de analizar dos de los aspectos fundamentales que trae consigo la apropiación de la "línea clara". Nos referimos, por un lado, a la recuperación del pacto lector que propone su poesía a partir de la publicación de La caja de plata (1985) en el contexto de la vuelta a la democracia en España y, por otro lado, a la forma en que la reestructuración del pacto lector de su poesía implica, al mismo tiempo, una recuperación de la dimensión figurativa del texto.

\section{La "línea clara" como pacto de lectura}

Y mientras tanto yo escribía poemas
que no se parecían en nada a los de antes
y que, en un cóctel raro, mezclaban clasicismo
con cotidianidad, dejando que la vida
y la cultura fuesen de la mano
en sus versos y, a veces, hasta dándose el pico.

(De Cuenca, 2014a: 89)

En la introducción de este trabajo mencionamos que, cuando de Cuenca descubre la "línea clara", se encontraba en un periodo de transición. A la vista de sus lectores, de hecho, en 1980 es todavía un poeta vinculado con la poesía novísima. Esa poesía que había florecido en las postrimerías del franquismo, se había caracterizado por su radical crítica de los relatos colectivos que cohesionaban la esfera pública española de ese entonces. En esta dirección, la labor corrosiva de esta generación fue, por un lado, la de intervenir la dicción del aparato oficial, deconstruyendo la mitología del régimen y resistiéndose a los discursos pedagógicos emanados de la industria cultural, y por otro lado, la de atacar el dispositivo verista de la poesía social -que había sido revisada ya por los poetas del cincuenta- acusándolo de un servilismo ideológico incompatible con el desarrollo artístico del texto. Acorralados por la utopía de "un franquismo sin Franco" y por la cada vez más lejana abolición del régimen por parte de la izquierda, estos poetas se abocaron a un virulento examen de la relación de la escritura con la sociedad y, en particular, con los proyectos colectivos que ésta barajaba. Bajo la consigna de la autonomía del arte, el 
discurso poético se abocó, por entonces, a una tarea de extenuante saturación culturalista, de asfixiante reflexión metapoética, de praxis aristocrática del exotismo y el malditismo o de veneración cuasi monástica del silencio. Una idée-force como la del desencanto, que tanta relevancia comienza a tener durante el tardofranquismo y a medida que la Transición avanza, parece haber sido el resultado -la somatización en el cuerpo social- de ese desajuste entre la palabra y la política (Labrador Méndez, 2009; Vilarós, 1998). La poesía novísima, en consecuencia, se irguió en torno de un pacto lector roto, de unas convenciones que habían perdido su conexión con la realidad y, en consecuencia, de un espacio y un tiempo extrañados. Como dijimos antes, la poesía de Luis Alberto de Cuenca se asociará durante la década del setenta con esta oleada generacional y sus libros de ese periodo responderán sin mayores objeciones a este horizonte ideológico y estético. Basta observar con detenimiento libros como Los retratos o Elsinore, en los que la escritura apuesta por el hermetismo, la opacidad técnica y conceptual y la intrincada erudición, para comprender cuán desafiante e inclusive cuán impenetrable era el pacto de lectura de su poesía en la década del setenta.

La publicación de La caja de plata (1985) marca un cambio rotundo en su poesía que, a partir de entonces, adoptará, en sus temas y estrategias textuales, una regularidad evidente que será asociada, tanto por el autor como por la crítica, a la expresión "línea clara". Este cambio puede comprenderse si observamos la emergencia de un contexto radicalmente diverso al que habían tenido de fondo las estéticas novísimas. La línea clara luisalbertiana, en este sentido, emerge en un momento que podríamos calificar como el de una "regeneración" de la vida democrática en España. Este periodo caracterizado en lo político por los pactos, consensos y concesiones, y por la implementación de una nueva retórica institucional, favorece la emergencia de una poesía dispuesta a renegociar su relación con la sociedad, con lo político y con lo público, y que, tal como observaría Miguel d’Ors, se lanza "en busca del público perdido" (1994). La singular combinación entre clasicismo y posmodernidad que adopta el dispositivo poético de la generación del ochenta provee, respectivamente, un repertorio de formas, códigos y lugares comunes y consensuados, y un nuevo orden que democratiza las prácticas culturales que 
comenzarán a pensarse ya en términos de consumo. La poesía, por lo tanto, vuelve a sentirse en condiciones de encontrar un "lugar" en la sociedad y de comprometerse con una tarea, indudablemente importante, como la de la reconstrucción de lo cotidiano. Luis García Montero es uno de los poetas que mejor comprende ese espacio en el que se inscribirá lo poético:

hay personas que se instalan en el futuro para imponer una idea del presente. Otras personas se instalan en el presente para discutir un modo de futuro. No es lo mismo hablar desde el futuro que discutir sobre el futuro. Lo primero suelen hacerlo los sacerdotes de la modernidad, los comisarios políticos y los poetas visionarios. Lo segundo lo hacen seres reales. Unos hablan como se escribe y nos meten en cintura con largos discursos envarados. Los otros escriben como se habla, como se habla entre amigos, con ese pudor entrañable, según decía Eliot, de las palabras privadas dichas en público.(García Montero, 1994: 113)

La focalización en el discurso de la intimidad, entendida por algunos poetas como una resistencia táctica a la lógica uniformadora de la globalización y el mercado, sin embargo, demarcará una zona para la poesía que gradualmente devendrá en un proceso de privatización. Sin recaer en el confesionalismo ni en la ingenuidad, el poema contendrá el registro de una sentimentalidad profundamente histórica y engarzada en un tejido social y político bien demarcado por una gestión institucional que la sostendrá (mediante eventos, premios, subsidios, etc.) como el reverso o complemento de lo público. Esta vinculación de la poesía con el concierto social se verá reflejada en la recuperación de un código común, una retórica de lo normal y un acercamiento no problemático a la realidad. El poeta, por lo tanto, se constituirá como un individuo involucrado activamente en el proceso de regeneración democrática, replicando hacia el interior del texto un nuevo pacto de convivencia. Es desde esta perspectiva como podemos entender el viraje, marcado como en ningún otro poeta, de Luis Alberto de Cuenca hacia un verismo implicado, por ejemplo, en la construcción de una épica de lo cotidiano o en la reformulación de una mirada a los temas menores. De esta forma, el dispositivo poético presentará una dimensión abiertamente menor que, en su aspiración por ofrecer un espacio accesible para el lector, acabará indagando 
en temas universales: el amor, la muerte, la amistad, etc. Ello puede observarse con claridad en esta reflexión en torno al término minor poet, hecha por De Cuenca:

\begin{abstract}
Normalmente, los poetas menores no deberían dedicarse a las letras mayores, sino a las diminutas. En este caso, el poeta menor es, además, miope y refractario (de momento) a las operaciones de miopía con rayo láser, y debe limitarse, pues, a encarar en sus versos temas gruesos, elementales, burdos, básicos. También los poetas de la Antología Palatina, con ser poetas menores, abordaban temas mayores, los llamados "temas de siempre", en los dísticos elegíacos de sus epigramas. De modo que el poeta miope y menor, al salir a la calle, no es capaz de leer más que las letras de los anuncios más grandes, los carteles mejor iluminados, los rascacielos, las autopistas. Ello quiere decir, trasladado a la esfera de los sentimientos, que el poeta cegato sólo es capaz de discernir, y en consecuencia de apreciar, pasiones evidentes como el amor, la amistad y el odio, y que, en el plano de las sensaciones, se limita a captar las menos sutiles, como placer, dolor, calor y frío. (De Cuenca, 2013: 26-27)
\end{abstract}

Esta perspectiva pretendidamente "miope" del poeta menor derivará, en el caso de nuestro autor, tal como anticipamos, en una comprensión del dispositivo poético en clave intimista. De esta forma, la constitución de un discurso de la intimidad y de lo cotidiano se presentará como clave de lectura no problemática y muchas veces anacrónica- de ciertas tradiciones que podríamos pensar como universales. El presente de la escritura -y su revés, la lectura- comienza a erosionar la distancia que la separa de la temporalidad recursiva de la tradición, haciendo tanto que la historia de la literatura y del arte puedan interactuar con ese discurso privado como que el dispositivo intimista pueda descifrar, acercarse y muchas veces tergiversar la distancia y la especificidad de las tradiciones abordadas. Ello puede comprobarse si leemos un texto titulado "Tu musa" en el que la invocación ritual de las divinidades -un procedimiento que, por ejemplo, tiene precedentes en la épica antigua- se confunde con la tónica del consejo amoroso:

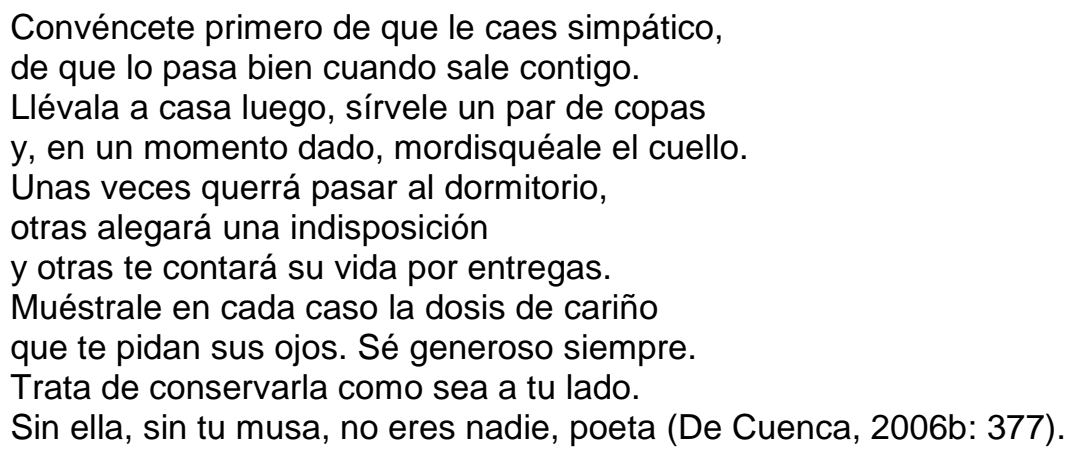


Lo que resulta realmente llamativo en la ironía que presenta este texto, es cómo se escenifica un horizonte emotivo cercano al lector, a partir de referencias a una cotidianidad reconocible y compartida, y cómo la invocación ritual es abordada desde esa experiencia actual. El poema, de esta forma, contiene, describe y reproduce un orden privado que se presenta como un posible modelo de lectura de la tradición. A su vez, la irrupción de un hipotexto tan general como evidente -la invocación a las musas- pone en suspenso la enunciación del consejo amoroso, estableciendo una distancia irónica que devela su carácter ficcional. Esta capacidad de la experiencia privada de leer la tradición y de la tradición de hacer legible la experiencia privada será un rasgo fundamental en su poesía. En otras palabras: en la poesía de Luis Alberto de Cuenca la tradición se vuelve íntima y la intimidad se vuelve tradicional.

Por fuera del campo de visión de esta "miopía" poética que construye, dentro de la cotidianidad, el imperio de lo menor, su poesía se verá contenida por una experiencia exterior, al mismo tiempo, colectiva o pública, que se figurará bajo una forma tópica: la calle. En otras palabras, este topónimo que conduce, de forma vaga y arquetípica, a cierta comprensión urbana del espacio, será el límite exterior de la experiencia de lo privado en su poesía. Ese espacio aparece claramente demarcado en el poema "La brisa de la calle":

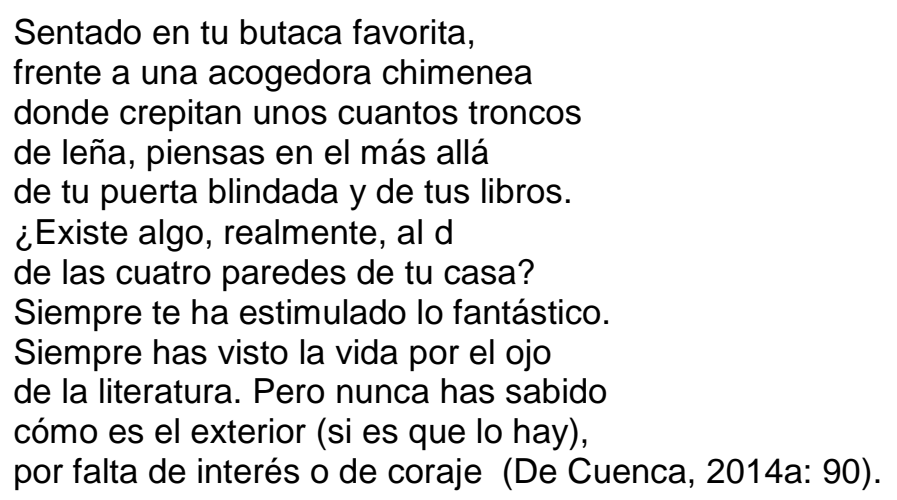

Sin embargo, la mirada menor en sus textos no implica que "la calle" sea un espacio ocluido, negado a su escritura. En este sentido, esta clara separación entre el espacio exterior (público y político) y el espacio interior (privado e íntimo) en el que se aloja el poeta, implicará un repliegue, como ya 
se dijo, hacia el intimismo, por un lado, y, por otro, hacia la construcción declaradamente hipercultural de lo colectivo. En sus propias palabras, tal como puede leerse en el ensayo también titulado "La brisa de la calle", este espacio exterior será comprendido en clave ficcional:

En familia, con tu ciudad, con tu mujer de carne y tus hijos, con la brisa a todo soplar en la calle, inventas tus poemas de poeta menor, tus epigramas. Son poemas con historia, en los que pasan cosas, como en los telefilmes americanos. Los personajes son como tú, como tu amada, como tus amigos (las amantes son, todas, apócrifas). Y se mueven y sueñan en medio de una ciudad absolutamente hiperreal, tan fantástica como la vida misma. (1990:106)

\section{"Línea clara": del realismo a la complicidad}

Pierre Fresnault-Deruelle explica que uno de los rasgos principales de la estética de "línea clara" en el cómic hergiano es la búsqueda de un "efecto de realidad" (1999: 13). Esta búsqueda, explica el autor de Hergé ou le segret de l'image, se impone, por un lado, ante la necesidad de mostrar ciertas zonas exóticas (el espacio colonial, por ejemplo) y, por otro, a la exigencia del "documentalismo" que preside esta producción historietística. Este doble movimiento, hacia la pedagogía de lo exótico y hacia la rigurosidad del detalle, no implica, como se podría imaginar, una inclinación hacia el naturalismo. Todo lo contrario, la técnica empleada por Hergé se caracteriza por un "geometrismo" que reduce la ambigüedad del trazo en busca de formas cerradas, convencionales y fácilmente reconocibles. La construcción de una ilusión referencial (Barthes, 1970; Riffaterre, 2017), por lo tanto, propone una zona común de "legibilidad", basada en ciertas convenciones pictóricas y narrativas que los lectores -los europeos, al menos- comprenden y comparten. Esta apuesta por la comunicación, en el caso de Hergé, además, se ve sustentada por la creación de una comunidad lectora que, a partir de la creación del semanario Tintín (1946), se autoproclamará tintinófila6 ${ }^{6}$ Por lo

\footnotetext{
${ }^{6}$ En este sentido, la línea clara implanta un pacto lector que es al mismo tiempo un modelo ético basado, por lo menos después de la Segunda Guerra Mundial, en los valores de la amistad y del respeto del prójimo. Este pacto lector facilita, a su vez, un acercamiento a la realidad que provee una forma de interpelación que se vuelca hacia lo político o hacia lo social. En este sentido, el modelo de héroe de las historietas de Tintín aspirará a una intervención individual que ponga en evidencia y haga colapsar un orden autoritario o injusto.
} 
tanto, la construcción de un verosímil realista, en las historietas de Hergé, se susrtentará menos en la capacidad técnica para reproducir la realidad que en la elaboración de un lenguaje historietístico capaz de consensuar ciertos lugares comunes con sus lectores. Esta operación que impulsa la "línea clara" -la de la construcción de un código representacional compartido que genere una apertura al público lector- es uno de sus elementos fundamentales y es precisamente uno de los aspectos en los que recaerá la lectura luisalbertiana del término.

En este sentido, la reconstrucción del pacto de lectura al que hacíamos referencia en el apartado anterior será la condición de posibilidad en la apropiación del estilo hergiano por parte de nuestro poeta. En otras palabras, ese consenso entre el poeta y el lector, que aparece diseñado bajo la alegoría de la claridad, es precisamente la condición convencional a partir de la cual es posible pensar una realidad para el poema. Esta dimensión consensuada de la experiencia poética consistirá en el registro de una voz normalizada que encuentra su conexión con el pasado a partir de una retórica conservadora, al mismo tiempo urbana, neoclasicista y posmoderna. La "línea clara", de esta forma, engarza un lenguaje actual -rico en expresiones y giros coloquiales y concertado en enunciaciones tópicas actualizadas- en una aceitada maquinaria retórica que remite, una y otra vez, a una tradición clásica, medieval o barroca. Rima, métrica regular, moldes estróficos tradicionales y tipos de composiciones de larga trayectoria se presentan como la superficie, por momentos invisible, en la que el lector se desplazará de forma no problemática. En esta dirección, la puesta en funcionamiento de este dispositivo poético habilita un viraje de la poesía luisalbertiana que, a diferencia de su etapa novísima, ahora sí puede aspirar a la figuración.

Este viraje, no obstante, no es un rasgo exclusivo de la "línea clara". Tanto la crítica como los mismos poetas observan que una gran parte de la poesía española durante la democracia tiene como rasgo fundamental la restitución de la ilusión referencial. Luis García Montero, por ejemplo, habla de "una vuelta a la realidad" y de la asunción de un tono verosímil (1996: 69). José Luis García Martín, por su parte, indica como dominante de la poesía del periodo la inclinación de estos poetas por la figuración, que se enfrenta a 
cualquier forma de vanguardismo que busque "sorprender antes que emocionar" (1992: 211). Miguel García Posada, al igual que diversos críticos del periodo (Eire, 2003; Lanz, 1998; Scarano, 2000), observa un generalizado "retorno a temas realistas" (1996). Esta inclinación hacia el realismo, la referencialidad y la figuración, sin embargo, viene acompañada por una reflexión metapoética, que recae sobre los mecanismos, artificios y estrategias que condicionan al texto poético. Leopoldo Sánchez Torre explica con claridad este movimiento doble:

\begin{abstract}
El poema realista se afirma como tal sin dejar de señalar su condición de artificio, por lo que se genera un potente entramado autorreferencial tendente a someter a control el pacto de lectura y formular las reglas del juego semiótico, convirtiéndose así en un mecanismo de dinamización de las convenciones que condicionan el funcionamiento de la comunicación poética y de las expectativas de lectura. Los poetas que nos ocupan recurrirán muy a menudo al uso de un dispositivo autorreferencial que va más allá de la simple reproducción de los tópicos temáticos clásicos (lo "indecible", la "cortedad del decir", el mundo como libro y tantos otros) -que, sin embargo, no desaparecen- para desplegarse como raíz y eje de todo un programa de escritura y para verbalizar el carácter paradójico de su propuesta de sentido: por un lado, la aspiración al restablecimiento del vínculo umbilical con la realidad exterior y, por otro, el señalamiento de la inesquivable ficcionalidad del poema(2004: 210).
\end{abstract}

La reflexión metapoética puede comprenderse si observamos con atención el carácter abiertamente convencional de estas escrituras. Jon Juaristi se refiere, en este sentido, al "pacto realista" presente en gran parte de la poesía del periodo; el realismo, entendido "como convención intersubjetiva", según explica el poeta vasco, "consiste en un acuerdo sobre los efectos de realidad del poema, no sobre los recursos para producirlos" (1994: 26). La construcción de este "pacto realista", tal como advierte Felipe Benítez Reyes, deja en evidencia el carácter ficcional del texto poético que ya no puede ser leído con ingenuidad (1989). Luis García Montero, por su parte, explica que esta distancia que atraviesa al texto poético, además, lo hace incompatible con la función de vehiculizar una ideología que le sea externa: 
No se trata de utilizar los poemas como medio de transporte de ideales anteriores, sino de ser capaces de crear realidades en los poemas, experiencias que sucedan en el texto de un modo verosímil para complicar el ánimo del lector y hacerlo cómplice, si es posible, de lo que ocurre en el texto; algo que pasa a través de las palabras, pero con la apariencia de que está pasando en la calle (1994: 112) .

Esta complicidad a la que hace referencia el poeta granadino es clave para entender cómo la irrupción de la "línea clara" en la poesía de Luis Alberto de Cuenca implica la creación de una zona común, un espacio de familiaridad y un horizonte experiencial mutuo para el poeta y su público lector. Es, por esta razón, además, por la que nuestro autor, al igual que muchos de sus compañeros de generación, vuelve a revivir una polémica poética como la que durante los cincuenta se vio entre quienes defendían la poesía entendida como comunicación y quienes sostenía su conexión con el conocimiento. Respecto de dicho enfrentamiento podemos recordar, de forma muy esquemática, que la primera acepción, estrechamente vinculada con la poesía de corte social que había imperado en la década del cincuenta, comprendía al texto poético como un vehículo no problemático de transmisión de contenido de conciencia, y la segunda acepción, de corte moderno y europeísta, valoraba el proceso poético en su dimensión epifánica y gnoseológica (Ferrari 2010: 10). El posicionamiento de Luis Alberto de Cuenca a favor de la poesía como comunicación será formulado tanto en textos poéticos como en diversos ensayos y entrevistas. Probablemente, el texto más evidente sea aquel titulado "Línea clara" en el que recrea la voz de un adversario para describirse:

Dicen que hablamos claro, y que la poesía no es comunicación, sino conocimiento, y que sólo conoce quien renuncia a este mundo (De Cuenca, 2006a: 13).

Este revival posmoderno de la polémica de medio siglo ${ }^{7}$, además de auspiciar una reformulación del pacto lector, pone sobre la superficie, tal como

\footnotetext{
7 En esta sintonía, en una entrevista que le fue hecha recientemente, deslizará: "Sin receptor no existe la creación artística. El arte aspira a la comunicación. Lo demás son tejemanejes masturbatorios" (De Cuenca, 2018b). De la misma forma, "El almendro y la espada", perteneciente al tríptico dedicado a Agustín de Foxá, también hará hincapié sobre el carácter comunicativo por el que aboga en la poesía: "Porque la poesía no ha de ser un tedioso / festín esencialista e incomprensible para / los miembros de una secta, sino una fiesta alegre / y comunicativa donde quepamos todos" (De Cuenca, 2010: 91).
} 
sucedía durante la década del cincuenta, un punto ciertamente conflictivo: la relación entre praxis poética y praxis política. La legibilidad por la que apuesta nuestro autor a partir de la publicación de La caja de plata, sin embargo, no puede pensarse en los mismos términos que los de la poesía social. Nada más lejano del tono beligerante y comprometido de aquellas poéticas: la defensa de la claridad expositiva que realiza nuestro autor parece apuntar a una dimensión más bien acomodaticia -más preocupada por establecer una distancia que la resguarde del ridículo que por sostener un apego ético, ideológico o políticoque, sin embargo, aspira a alcanzar un espacio relevante en el nuevo reparto democrático: el de la intimidad. Este espacio de relevancia -flujo interior de experiencia privada hacia lo público del que hablaba García Montero- en el caso de nuestro poeta, inclusive aparecerá como la búsqueda de un mercado para la poesía, algo que evidentemente puede observarse en su vinculación con géneros tan asociados al consumo como la canción ${ }^{8}$ o la historieta, e inclusive la reiterada afirmación de un público que no sea solamente el de la poesía. A continuación, podemos leer una declaración de De Cuenca, que deja en evidencia esto que explicamos:

\begin{abstract}
En ese sentido yo creo que sí que hay un error de base en conceptuar la poesía como algo minoritario. Es cierto que hay un determinado tipo de poesía más hermético y menos comunicativo. Pero la poesía que hago yo, la poesía que hace Margarit, la de Roger Wolfe, la de Manuel Vilas, la poesía que hacen tantos otros poetas que están vivos ahora y que han optado por la comunicación, esa, indudablemente, podría llenar estadios si hubiera algún empresario que lo apoyara y si hubiera un márquetin que lo acompañara. (De Cuenca, 2015)
\end{abstract}

La construcción del dispositivo poético no podrá sustraerse a una circulación que lo encuentra como objeto de consumo, sometido a la lógica de la publicidad y el marketing, de la remediación y el amusement, pero también sujeto a mecanismos claramente delimitados de circulación y consagración en

\footnotetext{
${ }^{8}$ La conexión entre poesía y público suele aparecer bastante en declaraciones de nuestro poeta. Un ejemplo de ello es la narración de su encuentro musical con Orquesta Mondragón durante la década del ochenta: "A Gurruchaga le conocía de la mili un amigo mío. Y de hecho fue él quien le avisó de que podía presentarle a un poeta que podía ayudarle con sus próximos proyectos musicales. (...) Javier venía de la escena underground, pero al parecer quería cambiar su estilo para atraer más a todos los públicos, y no sólo a mayores con reparos. En ese sentido nuestro amigo pensó que yo podía serle útil" (Jiménez, 2019).
} 
circuitos institucionales bien demarcados. Ello se puede observar en el poema ya mencionado "Línea clara":

Dicen que hablamos claro y que nos repetimos

de lo claro que hablamos, y que la gente entiende

nuestros versos, incluso la gente que gobierna,

lo que trae consigo que tengamos acceso

al poder y a sus premios y condecoraciones,

ejerciendo un servil e injusto monopolio. (De Cuenca, 2006a: 13)

La complicidad, en este sentido, apunta a la creación de un pacto de lectura que, bajo una forma individual, normalizada y privada $^{9}$, pudiera dar cuenta de una realidad política y social, por lo menos para la década del ochenta, novedosa, como la que se abría camino con la democracia. En esta sintonía, llama poderosamente la atención la complementariedad entre una práctica pública de nuevas regulaciones sobre la vida en comunidad (nuevas prácticas, nuevas libertades, nuevos consumos) basadas en los consensos y pactos $^{10}$, y una praxis poética que se compromete a dotar de una retórica clásica -normal y normalizada- a la experiencia cotidiana de una nueva ciudadanía ${ }^{11}$.

La complicidad, que por entonces llega a pensarse como una opción superadora de la dicotomía comunicación vs. conocimiento ${ }^{12}$, es también,

\footnotetext{
${ }^{9}$ En el artículo "Los argumentos de la realidad", García Montero escribirá: "La poesía significa tomarnos a nosotros mismos en serio y ser capaces de establecer alguna trascendencia, lazos de complicidad con el lector. Esta complicidad no se consigue haciendo rebajas y arte populachero, sino pensando en uno mismo como persona normal." (García Montero, 1994: 113)

10 Nos referimos particularmente al "Acuerdo sobre el programa de saneamiento y reforma de la economía" y "Acuerdo sobre el programa de actuación jurídica y política", conocidos como los "Pactos de la Moncloa" que fueron redactados durante 1977, y a la Constitución de 1978.

${ }_{11}$ Eso parece desprenderse de las palabras de Luis García Montero cuando reclama la profesionalización del oficio poético: "La profesionalización de la poesía, el conocimiento riguroso del oficio, no tiende ahora a crear una distancia original entre el lenguaje del poema y el de la sociedad. La profesionalización coincide en este caso con una voluntad de ciudadanía." (García Montero, 2003: 22)

12 De este modo, Dionisio Cañas llegará a conciliar los dos extremos de la polémica con la alternativa superadora de la complicidad: "En realidad, este trabajo se podría llamar crónica de una muerte anunciada, porque desde un principio les puedo decir que la famosa polémica entre poesía como comunicación y poesía como conocimiento ocurrió sólo en el papel, pero en la conciencia de cada uno de los miembros que participaron en ella estaba bien claro que la poesía es ambas cosas: conocimiento y comunicación. $\mathrm{O}$, para resumirlo en un solo concepto, la poesía es complicidad: complicidad con toda la poesía escrita anteriormente, con la cultura, tanto elitista como popular, complicidad del poeta consigo mismo, con el mundo, con el lector (1996: 3)
} 
como decíamos, la demarcación de un espacio en la sociedad para la poesía, que inclusive reclamará para sí una "utilidad" (García Montero, 1993). Por esta razón, ese espacio interpersonal, que aúna al lector y al autor, se emparenta con una experiencia compartida: la de la resistencia a la uniformación y racionalización posmoderna y la de las trayectorias de consumos culturales democratizados. Esta experiencia compartida, sin embargo, en el caso de nuestro poeta, a diferencia de la tendencia experiencial identificada con la obra de Luis García Montero, tenderá a la desideologización del texto. La consolidación de un dispositivo clasicista, formalmente conservador, coincidirá, en este sentido, con un posicionamiento textual que se presenta como apolítico $^{13}$. Ello puede verse, como ya se dijo, en el despliegue de una dimensión menor de aspiración universalista en su poesía. Basta observar un poema como "Cómplice de un crimen", perteneciente a La vida en llamas para comprender cómo la exploración de la veta amorosa desplaza el hipotexto baudeleriano ${ }^{14}$ hacia un espacio universal:

\author{
En el Libro de Oro de la escuela \\ donde estudiaba Carlos Baudelaire \\ figuraba esta frase lapidaria: \\ 'El amor es un crimen en que tienes \\ que contar por lo menos con un cómplice.' \\ Pues claro que lo es. Sin duda alguna, \\ el amor es un crimen. Otras cosas
}

\begin{abstract}
13 Esta postulación del carácter apolítico de la escritura aparece claramente en sus intervenciones públicas. Sirva de ejemplo la siguiente declaración en la que polemiza sobre la identificación, en España, de la cultura con los posicionamientos de izquierda: "Yo he escrito algunos textos atacando esa identificación de la cultura con la izquierda porque no me parece más que una cuestión hispánica. Como aquí hemos tenido una historia muy reciente, ligada a una dictadura de hace casi 40 años, obviamente la gente que se ha planteado hacerse preguntas desde el punto de vista intelectual, ha optado por la izquierda. En el mundo que estuvo sometido al comunismo en el este de Europa, sucede lo contrario. Por lo general, ahora mismo en Rumanía, en Polonia, en la República checa, casi todos los intelectuales son conservadores. En España sucede al revés y yo creo que con el tiempo se irá corrigiendo, porque, evidentemente, hay que decir muy alto y muy claro que la cultura no es ni de izquierdas, ni de derechas, ni de centro, ni de ninguna parte. La cultura es una de las manifestaciones que tiene el ser humano y el ser humano, estructuralmente, no tiene nada que ver con las ideologías" (De Cuenca, 2014b).

14 Resulta curioso cómo Luis Alberto de Cuenca redirecciona -por no decir, tergiversa- el sentido de la cita baudeleriana, proveniente de una entrada de sus Diarios íntimos, en busca de una comprensión no problemática: "Hay ciertas mujeres que se parecen a la cinta de la Legión de Honor. No se las quiere porque se ensuciaron contra ciertos hombres. Por la misma razón que yo no me pondría los calzoncillos de un sarnoso. Lo que el amor tiene de aburrido es ser un crimen, para el cual se necesita un cómplice" (Baudelaire, 2020: 27).
\end{abstract}




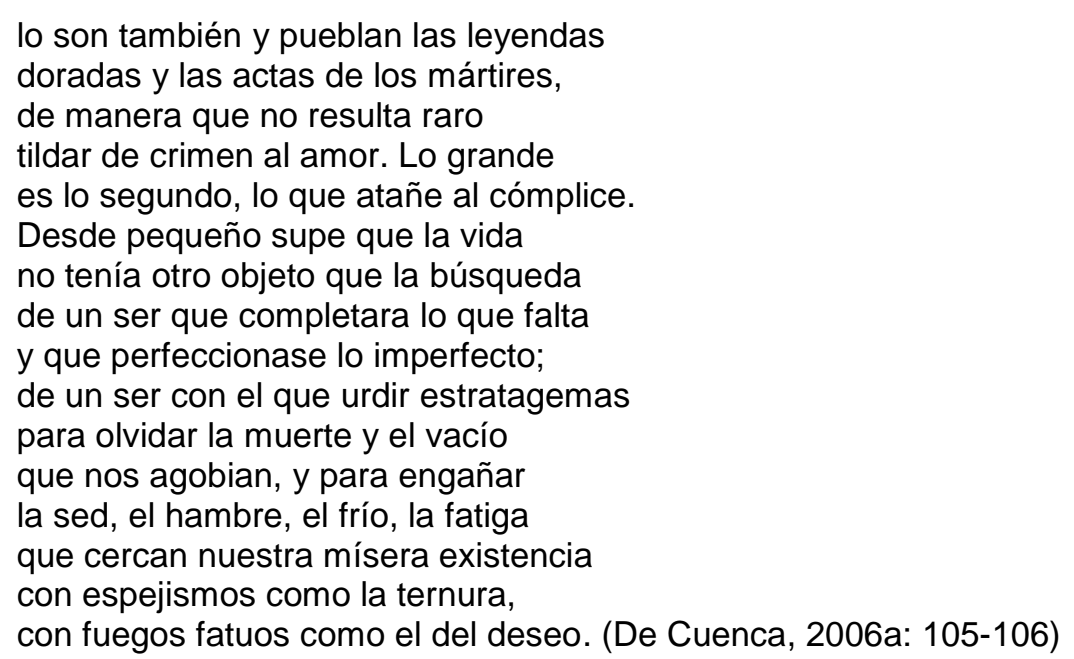

\section{Conclusión}

En el principio del artículo narramos las circunstancias en las cuales el poeta Luis Alberto de Cuenca había comenzado a interesarse por el estilo historietístico de George Remi. El descubrimiento de la "línea clara" por parte del escritor madrileño marca el inicio de un derrotero poético que acabará definiendo los contornos de su obra. La aparición de la "línea clara" implicará la irrupción de una dimensión crítica que, por un lado, le permitirá ubicarse en un contexto de producción específico y, por otro, habilitará un espacio de reflexión respecto de su propio pasado. Efectivamente, será la apropiación de esta expresión en su obra la que permitirá desplegar una estética que, sin confrontar con la poesía de la experiencia, sabrá diferenciarse de ella y, al mismo tiempo, le permitirá distanciarse de su aventura novísima o, por lo menos, ponerla en perspectiva.

Este trabajo se ha propuesto analizar dos aspectos fundamentales de esta apropiación poética. El primero, como pudimos observar, se encuentra vinculado con la inscripción de la línea clara luisalbertiana en un contexto cultural e histórico determinado. Su poesía, en efecto, se adhiere ideológicamente a cierta zona mayoritaria de la producción poética desarrollada durante la vuelta a la democracia y participa activamente del proceso de regeneración ciudadana, como planteamos, a través de una evidente privatización de la experiencia poética. Desde esta perspectiva, la línea clara luisalbertiana implica la construcción de una épica de lo cotidiano y 
una mirada decididamente menor, cuya barrera de contención parece estar dada por una exterioridad urbana. La clara demarcación del espacio de lo poético, a su vez, habilitará la construcción de una dimensión consensuada y convencional en la que la experiencia poética se volverá, otra vez, accesible. El segundo aspecto de la apropiación poética de la expresión "línea clara" que pudimos analizar se encuentra vinculado con el carácter retórico y artificioso de esta accesibilidad de los textos luisalbertianos. La consolidación de un dispositivo retórico, como se dijo, normalizado, conservador, clasicista y posmoderno, será la condición de base que le permitirá al autor poder aspirar a una figuración convencional. En esta dirección, la recuperación de un pacto lector privado tendrá como principal consecuencia el afianzamiento de una complicidad que pondrá en sintonía la experiencia histórica y cultural del poeta con la de sus lectores y que, en el caso de nuestro autor, implicará un proceso de desideologización de la experiencia poética.

\section{BiBLIOGRAFÍA}

AlARY, Viviane (2002). "El final de los setenta y la década de los ochenta: la proliferación de revistas y las grandes inquietudes". En ALARY, Viviane; GuBERN, Román (eds.). Historietas, comics y tebeos españoles. Toulouse: Press Universitaire de Miraile, pp. 93-110.

Arroyo Almaraz, Antonio (2012). "Poética posmoderna transversal a las artes y la literatura: línea clara". En Alemany FerReR, Rafael; Chico Rico, Francisco (eds.), Literatura $i$ espectacle. Alicante: Servicio de Publicaciones Universitat d'Alacant, pp. 53-62.

BARTHES, Roland (1970). "El efecto de realidad". En Verón, Eliseo (ed.), Lo verosímil. Buenos Aires: Editorial Tiempo Contemporáneo, pp. 95-101.

BAudelaiRE, Charles (2020). Diarios íntimos. La Canyada: NoBooks Editorial.

Benítez Reyes, Felipe (1989). "La poesía como interés privado". Renacimiento: revista de literatura, $n .-3, \mathrm{~s} / \mathrm{p}$.

BufILL, Juan et al. (1984). Tintín a Barcelona. Homenatge a Hergé. El Museu Imaginari de Tintín. Barcelona: Fundación Joan Miró.

CAÑAS, Dionisio (1996). "La poesía como complicidad. Las polémicas poéticas de los años 50". En DiputAción GENERAL DE ARAGÓN; DEPARTAMENTO DE CULTURA Y TURISMO. Jaime Gil de Biedma y su generación literaria. Zaragoza: Diputación Provincial, pp. 3-44.

CASTILlO CÁCERES, Fernando (2011). Tintín-Hergé: una vida del siglo XX. Madrid: Fórcola Ediciones.

CenverA, Juan (1992). Teoría de la literatura infantil. Valencia: Ediciones Mensajero.

De CuencA, Luis Alberto (2006a). La vida en llamas. Madrid: Visor. 
De CuencA, Luis Alberto (2006b). Poesía (1979-1996). Madrid: Cátedra. De CuenCA, Luis Alberto (2014a). Cuaderno de vacaciones. Madrid: Visor. De CuencA, Luis Alberto (2014b). "Luis Alberto Cuenca: 'La cultura no es de izquierdas ni de derechas", http://www.ieturolenses.org/revista turia/index.php/actualidad turia/cat/c onversaciones/post/luis-alberto-cuenca-la-cultura-no-es-de-izquierdas-nide-derechas/ [Fecha de consulta: 2 de mayo de 2021]

DE CUENCA, Luis Alberto (2010). El reino blanco. Madrid: Visor.

De CuencA, Luis Alberto (2011). "Prólogo". En CAstillo CÁCeres, Fernando. Tintín-Hergé: una vida del siglo XX. Madrid: Fórcola Ediciones.

DE CuENCA, Luis Alberto (2013). "La alegre brisa de la literatura". En FUNDACIÓN MARCH. Luis Alberto de Cuenca. Madrid: Fundación Juan March.

De CuencA, Luis Alberto (2015). "Luis Alberto de Cuenca: 'Hay que mezclar a Homero con Spiderman'", en http://dialogados.com/entrevista-luisalberto-de-cuenca-cultura-filologia-poesia-homero-spiderman/ [Fecha de consulta: 2 de mayo de 2021]

EIRE, Ana (2003). "La poesía de la experiencia en la postmodernidad: un acercamiento a la nueva poesía española a través de la obra de Luis García Montero, Miguel d'Ors y Andrés Trapiello". Hispania, 86, 2, pp. 220-230.

FERRARI, Marta Beatriz (2010). Vivir con las palabras: poesía y pensamiento en Carlos Marzal. Mar del Plata: EUDEM.

Fresnault-Deruelle, Pierre (1999). Hergé ou Le secret de l'image: essai sur l'univers graphique de Tintin. Bruxelles: Moulinsart.

GARcía MARTín, José Luis (1992). La poesía figurativa: crónica parcial de quince años de poesía española. Sevilla: Renacimiento.

García Montero, Luis (1993). "¿Por qué no sirve para nada la poesía?". En García Montero, Luis et al. ¿Por qué no sirve para nada la poesía? Madrid: Hiperión, pp. 7-41.

García Montero, Luis (1994). "Los argumentos de la realidad". Diablotexto:

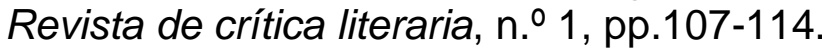

García Montero, Luis (1996). Aguas territoriales. Madrid: Pre-Textos.

García MONTERO, Luis (2003). "Poetas políticos y ejecutivos bohemios". En MARISCAL, José M.; PARDo, Carlos. Hace falta estar ciego (Poéticas de compromiso para el siglo XXI). Madrid: Visor, pp. 11-23.

GARcíA-PoSADA, Miguel (1996). La nueva poesía (1975-1992). Barcelona: Crítica.

JimÉnEZ, Nieves (2019). "Canciones completas. Luis Alberto de Cuenca", en https://eltorotv.com/opinion/tribunas/canciones-completas-luis-albertocuenca-opinion-tribuna-20190617 [Fecha de consulta: 2 de mayo de 2021]

JUARISTI, Jon (1994). "El pacto realista". Ínsula, n. 565, enero, 1994, pp. 25-26.

LABRADOR MÉNDEZ, Germán. (2009). Letras arrebatadas. Poesía y química en la transición española. Madrid: Devenir.

LANZ, Juan José (1998). "La joven poesía española. Notas para una periodización", Hispanic review, n.ㅇ 66, pp. 261-87.

LANZ, Juan José (2006). "Introducción”. En DE CuenCA, Luis Alberto, Poesía (1979-1996). Madrid: Cátedra. 
LetRÁN, Javier (2005). La poesía postmoderna de Luis Alberto de Cuenca. Sevilla: Editorial Renacimiento.

D’ORs, Miguel (1994). En busca del público perdido: aproximación a la última poesía española joven (1975-1993). Granada: Impredisur.

Peeters, Benoît (2013). Hergé, el hijo de Tintín. Madrid: Confluencias.

RIfFATERRE, Michael (2017). "La ilusión referencial". Co-herencia, 14, 27, pp. 13-37.

SÁNCHEZ TORRE, Leopoldo (2004). "Realismos y autoreferencia en la poesía última española". CELEHIS: Revista del Centro de Letras Hispanoamericanas, n.ำ 16, pp. 207-28.

SCARANO, Laura (2000). "La otra porsmodernidad: reflexiones sobre España desde Argentina". CELEHIS: Revista del Centro de Letras Hispanoamericanas, $\mathrm{n} . \mathrm{0} 12$, pp. 257-281.

SuÁREZ MARTínEZ, Luis Miguel (2010). La tradición clásica en la poesía de Luis Alberto de Cuenca. Pontevedra: Editorial Academia del Hispanismo.

Tendero, Arturo (2008). "Luis Alberto de Cuenca". Otro lunes. Revista Hispanoamericana de Cultura, n. ${ }^{\circ}$ 8, pp. 9-12.

VILARós, Teresa (1998). El mono del desencanto: Una crítica cultural de la transición española (1973-1993). Madrid: Siglo XXI.

Fecha de recepción: 12 de mayo de 2021

Fecha de aceptación: 13 de diciembre de 2021 